\title{
The Effect of Decomposed Microstructure on Mechanical Properties of Additively Manufactured Ti-6Al-4V Alloy
}

\author{
Desrilia Nursyifaulkhair*, Nokeun Park ${ }^{*, * *, \dagger}$, and Eung Ryul Baek*,**,† \\ *School of Materials Science and Engineering, Yeungnam University, Gyeongsan, 38541, Korea \\ **Institute of Materials Technology, Yeungnam University, Gyeongsan, 38541, Korea \\ †Corresponding author: †nokeun_park@yu.ac.kr, †'erbaek@yumail.ac.kr \\ (Received May 20, 2021; Revised June 30, 2021; Accepted August 2, 2021)
}

\begin{abstract}
This study investigated the effect of microstructural decomposition on the mechanical properties of additively manufactured Ti-6Al-4V by directed energy deposition. The formation of a' martensite and a massive phase $\left(a_{m}\right)$ was observed in the deposited layers. The $a^{\prime}$ and $a_{m}$ in the lastly deposited layer appeared as a needle-shaped and a sub-lamellar structure, respectively. However, the morphology of $a^{\prime}$ and $a_{m}$ was decomposed in the lower layers due to the intrinsic heat treatment. Moreover, The heat conduction rate calculation showed that the lower powder feed rate generates more heat conduction. Therefore, the microstructure was further decomposed for the specimen with a lower powder feed rate. These phenomena consequently affected the mechanical properties and fracture behavior of the Ti-6Al-4V alloy.
\end{abstract}

Key Words: Titanium alloys, LASER, Intrinsic heat treatment, Microstructure, Mechanical properties

\section{Introduction}

For decades, titanium alloys have become one of the most attractive engineering materials for various applications, such as aircraft and biomedical industries, due to their low density, superior mechanical properties, and excellent corrosion resistance. Ti-6Al-4V, classified as $\alpha+\beta$ titanium alloy, dominates more than half of the total titanium usage ${ }^{1)}$. Ti- $6 \mathrm{Al}-4 \mathrm{~V}$ is the most widely used among other titanium alloys since it has complex microstructures that can be modified to improve mechanical properties ${ }^{2,3}$. Furthermore, this alloy also has a lower cost compared to the high-strength $\beta$ titanium alloy.

Owing to the high demand for Ti-6Al-4V, several manufacturing methods have been utilized to fulfill the necessity. Ti-6Al-4V is conventionally fabricated using casting and forging, followed by machining to precisely tailor the final dimension ${ }^{4}$. However, these conventional methods are disadvantageous due to inefficient materials usage, ineffective lead time, high-cost processes $^{5}$. To overcome the issues, additive manufacture
(AM) has been developed as a promising technology to fabricate a three-dimensional net-shaped product in a manner of layer-by-layer. The feature of net-shaped can minimize the material waste, which increases the buy-to-fly ratio and subsequently enhances the cost-effectiveness ${ }^{6,7)}$. AM can be divided into powder bed fusion (PBF) and directed energy deposition (DED) based on the principle process. A prior study reported that DED exhibited a higher deposition rate and material efficiency than $\mathrm{PBF}^{8,9)}$. Therefore, the DED becomes a potential process to fulfill the high demand for Ti-6Al-4V. In DED Ti-6Al-4V, the microstructures of $\alpha^{\prime}$ martensite and $\alpha$ massive phase $\left(\alpha_{\mathrm{m}}\right)$ are generally formed due to the high cooling rate introduced during the process $^{10)}$. The $\alpha^{\prime}$ and $\alpha_{\mathrm{m}}$ usually are observed with the appearance of acicular and sub-lamellar morphology, respectively ${ }^{11)}$. However, the microstructures of $\alpha^{\prime}$ and $\alpha_{\mathrm{m}}$ in the lower layer experience intrinsic heat treatment due to the repetition of subsequent layers during building the product ${ }^{12,13}$. Accordingly, the microstructures of $\alpha$ ' and $\alpha_{\mathrm{m}}$ can be decomposed when subjected to the intrinsic heat treatment, which is unavoidable heat trans-

Journal of Welding and Joining, Vol.39 No.5(2021) pp527-535

https://doi.org/10.5781/JWJ.2021.39.5.9 
fer from the melt pool of the upper layer. Meanwhile, the extrinsic heat treatment is a subsequent heat treatment of the alloy after DED fabrication, which is usually conducted using a furnace. The alteration in the morphology of $\alpha$ ' and $\alpha_{\mathrm{m}}$ consequently can affect the mechanical properties of the Ti-6Al-4V. This present study mainly investigates the influence of the $\alpha^{\prime}$ and $\alpha_{\mathrm{m}}$ decomposition on the mechanical properties of the additively manufactured Ti-6Al-4V alloy by DED.

\section{Experimental Methods}

The AM Ti-6Al-4V with a total number of 10 layers was manufactured using DED by depositing the alloy powder on a Ti-6Al-4V substrate. The alloy powder was fabricated using a plasma atomization process, resulting in an average powder size of $90 \mu \mathrm{m}$. During DED, the powder feed rate was varied at 3, 6, and 9 $\mathrm{g} \cdot \mathrm{min}^{-1}$, while the laser power and the scan speed were set at the constant values of $900 \mathrm{~W}$ and $900 \mathrm{~mm} \cdot \mathrm{min}^{-1}$, respectively. The schematic of the DED process in this work is illustrated in Fig. 1a. Subsequently, the deposited alloy was cut from the substrate for further microstructural and mechanical properties examinations.

For the microstructure observation, all specimens were initially ground using $\mathrm{SiC}$ paper until 2400-grit, followed by mechanical polishing using $1-\mu \mathrm{m}$ diamond suspension. The specimens were then etched using Kroll's reagent with the composition of 85 vol.\% distilled water, 10 vol.\% nitric acid, and 5 vol.\% hydrofluoric acid. Optical microscopy (OM) and scanning electron microscopy (SEM) were conducted to measure the microstructure at the center region of the bottom to the top layer of the deposited Ti-6Al-4V alloy. As for the characterization of mechanical properties, Vickers microhardness and tensile tests were conducted at room temperature. The Vickers microhardness test with a load of $1 \mathrm{kgf}$ and a dwell time of $10 \mathrm{~s}$ was performed at the center region of the bottom to the top layer. For the tensile test, flat dog-bone-shaped specimens (Fig. 1b) with a gauge length of $5 \mathrm{~mm}$, a gauge width of $2.5 \mathrm{~mm}$, and a thickness of $1 \mathrm{~mm}$ were prepared by an electrical discharge machining. The position of the tensile test specimens was identified to be located in layers 5-6. Prior to the tensile test, the specimens were ground by 2400-grit $\mathrm{SiC}$ paper to eliminate any surface defect and set $1 \mathrm{~mm}$ in thickness precisely. The tensile test with a strain rate of $8.3 \times 10^{-4} \mathrm{~s}^{-1}$ was conducted at room temperature. The digital image correlation (DIC) technique by VIC-2D software was then utilized for precise strain distribution on the surface of the tensile specimens.

\section{Results}

Figs. 2 and 3 show the formation of $\alpha$ ' and $\alpha_{\mathrm{m}}$, respectively, within the prior $\beta$ grain of the as-built DED Ti-6Al-4V alloy, as a result of high cooling rate (beyond 4000 $\left.\mathrm{K} \cdot \mathrm{s}^{-1}\right)$ in the DED process ${ }^{10)}$. The $\alpha^{\prime}$ generally appears as a needle-shaped morphology, as shown at the top layer of the specimens in Figs. 2a-2c. On the other hand, the $\alpha$ ' seems to be partially decomposed in the middle layer of the specimens (Figs. 2d-2f). The morphology of $\alpha$ ' in layer 6 shows a combination of needle-shaped and lamellae morphology. A fully decomposed $\alpha$ ' was further observed in layer 2 (Figs. $2 g-2 i$ ), in which the $\alpha$ lamellae was surrounded by the $\beta$ phase. As for the $\alpha_{m}$ observation, the $\alpha_{m}$ in the top layer exhibits a sub-lamellar structure (Figs. 3a-3c), which is similar to the previous study ${ }^{11)}$. In the middle layer, the morphology of $\alpha_{\mathrm{m}}$ exhibits a more continuous lamellar structure

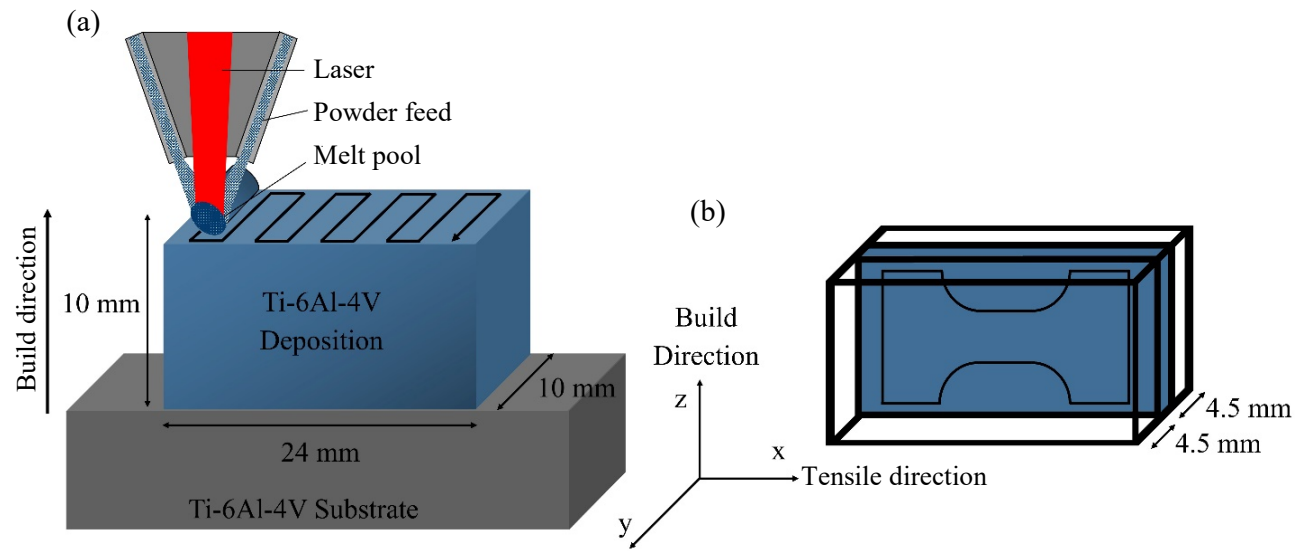

Fig. 1 Schematic of (a) the DED process for manufacturing a specimen with dimensions $24 \times 10 \times 10 \mathrm{~mm}^{3}$, and (b) the orientation of the tensile specimen, which is perpendicular to the build direction. The position of the tensile test specimens is located in the middle layers of the deposited alloy 

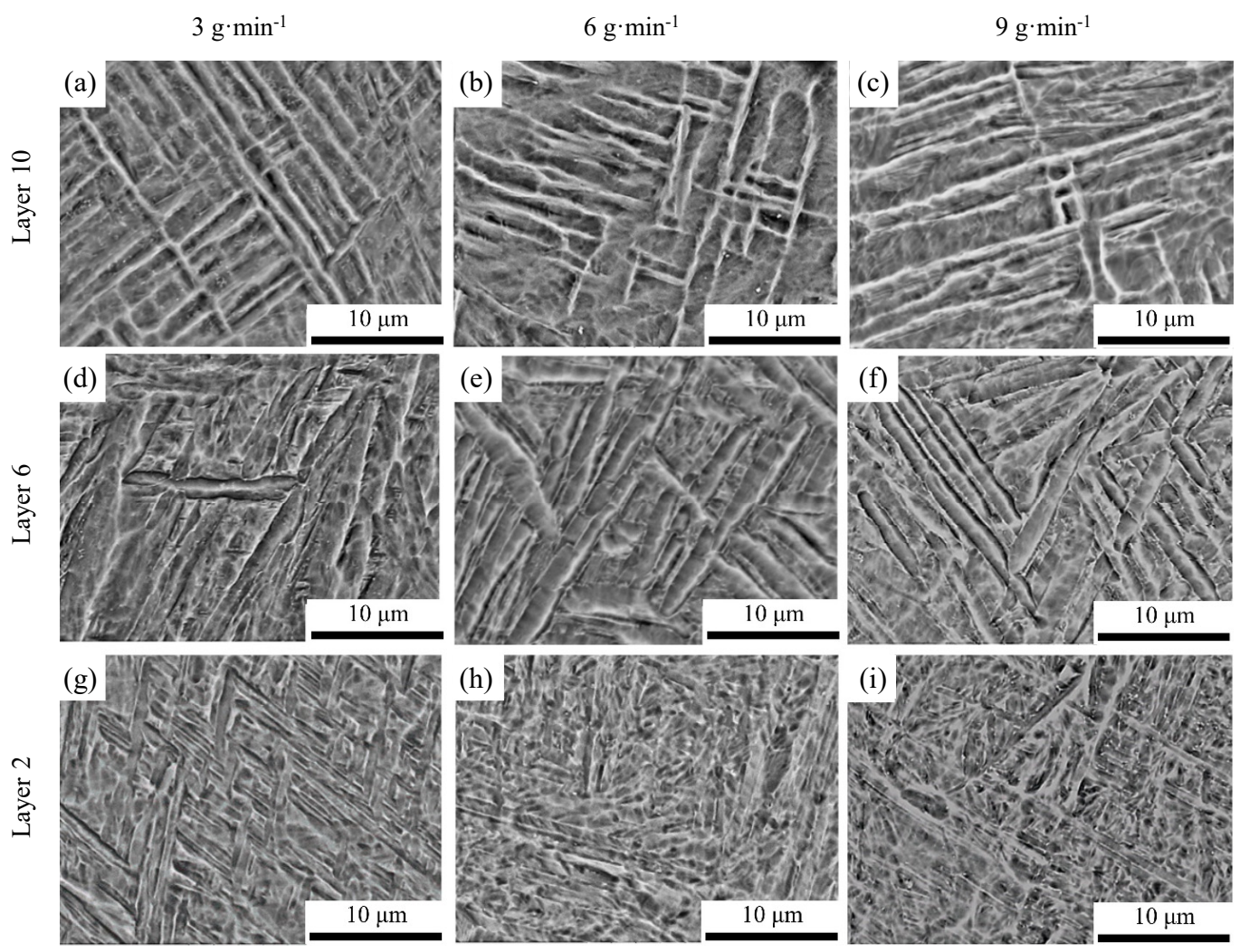

Fig. 2 The a' martensite in the center region of the top, middle, and bottom layers for the specimens with the different powder feed rates: $(\mathrm{a}, \mathrm{d}, \mathrm{g}) 3 \mathrm{~g} \cdot \mathrm{min}^{-1},(\mathrm{~b}, \mathrm{e}, \mathrm{h}) 6 \mathrm{~g} \cdot \mathrm{min}^{-1}$, and $(\mathrm{c}, \mathrm{f}, \mathrm{i}) 9 \mathrm{~g} \cdot \mathrm{min}^{-1}$
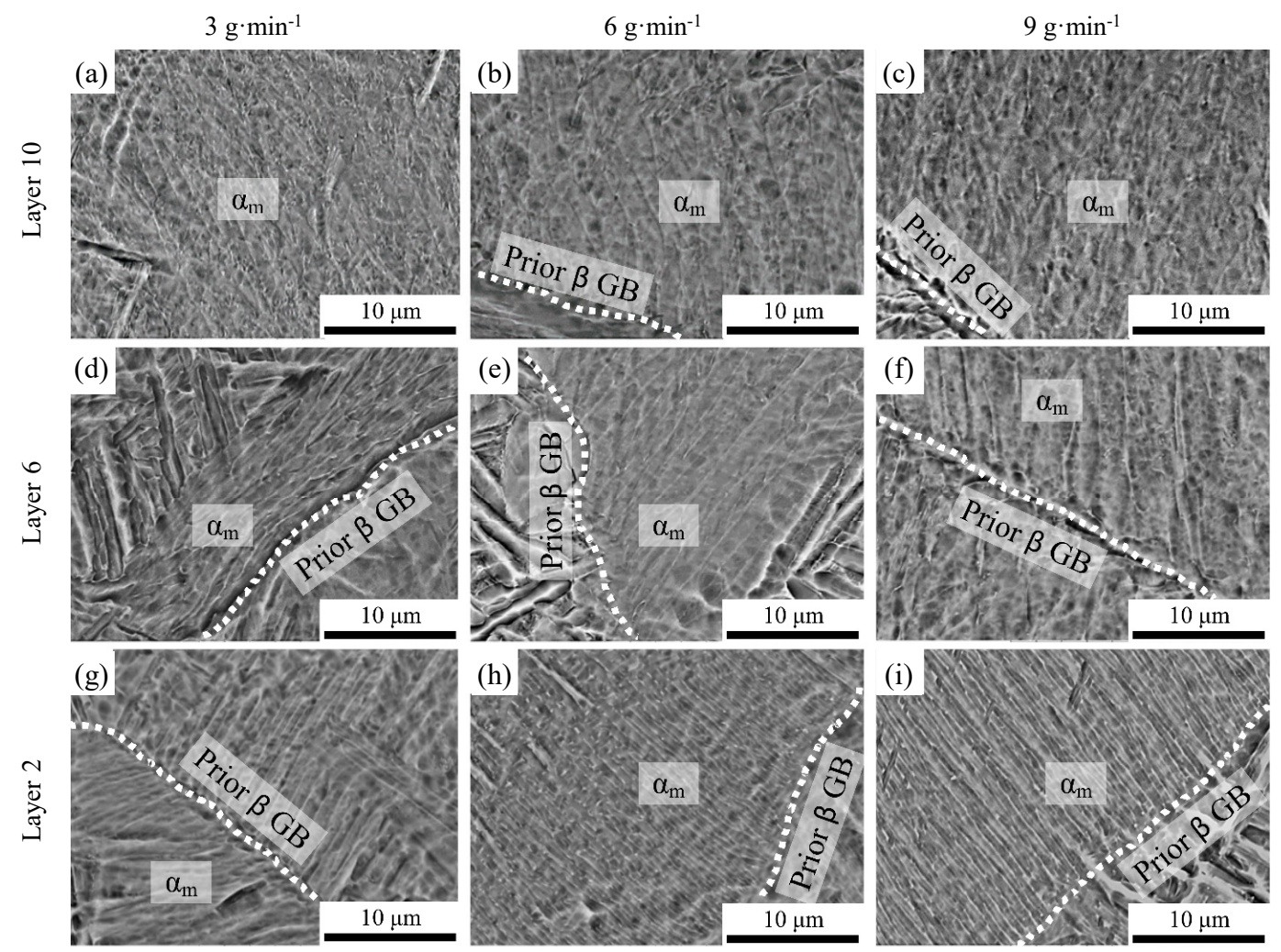

Fig. 3 The $a_{m}$ phase in the center region of the top, middle, and bottom layers for the specimens with the different powder feed rates: $(\mathrm{a}, \mathrm{d}, \mathrm{g}) 3 \mathrm{~g} \cdot \mathrm{min}^{-1},(\mathrm{~b}, \mathrm{e}, \mathrm{h}) 6 \mathrm{~g} \cdot \mathrm{min}^{-1}$, and $(\mathrm{c}, \mathrm{f}, \mathrm{i}) 9 \mathrm{~g} \cdot \mathrm{min}^{-1}$, The white dashed lines indicate the prior $\beta$ grain boundary 
compared to that in the top layer (as shown in Figs. 3d-3f). A thinner formation of $\alpha_{\mathrm{m}}$ with the $\alpha$ thickness of $0.5 \mu \mathrm{m}$ was further observed in the bottom layer of the specimens (Figs. 3g-3i). Moreover, according to Figs. 2 and 3, the microstructure was further decomposed for the specimen with a lower powder feed rate.

Fig. 4 displays the hardness tendency in the deposited layers for specimens with the powder feed rates of 3,6 ,

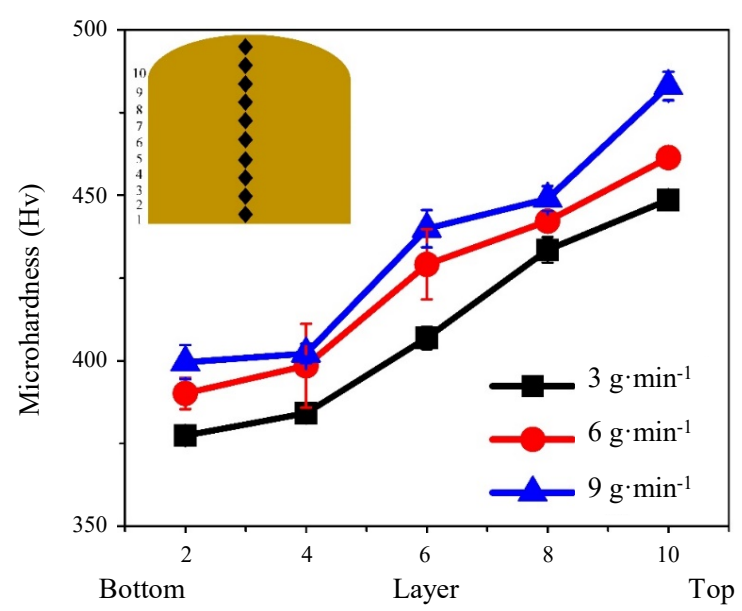

Fig. 4 Hardness variation of the specimens with the powder feed rates of 3,6 , and $9 \mathrm{~g} \cdot \mathrm{min}^{-1}$ from the bottom to the top layer and $9 \mathrm{~g} \cdot \mathrm{min}^{-1}$. The hardness values in the bottom layer varied from $375 \mathrm{HV}$ to $400 \mathrm{HV}$ depending on the powder feed rate. The hardness values increase gradually with higher deposited layers, reaching up to 450-480 $\mathrm{HV}$ in the top layer. This phenomenon can be correlated with the alteration of the $\alpha$ ' and $\alpha_{\mathrm{m}}$ microstructural morphology. These hardness values are generally higher than those in Ti-6Al-4V produced using other fabrication methods ${ }^{14,15)}$ and the substrate's mean hardness (356 HV). Furthermore, it is noticed the hardness values increase with the increasing powder feed rate, and the specimen with the powder feed rate of $9 \mathrm{~g} \cdot \mathrm{min}^{-1}$ exhibits the highest hardness values among the other specimens in this study.

The tensile test results of the DED Ti-6Al-4V specimens with the powder feed rates of 3 and $6 \mathrm{~g} \cdot \mathrm{min}^{-1}$ are shown in Fig. 5a. The specimen with the powder feed rate of $9 \mathrm{~g} \cdot \mathrm{min}^{-1}$ could not be tensile tested owing to a severe lack of fusion. Both specimens with the powder feed rates of 3 and $6 \mathrm{~g} \cdot \mathrm{min}^{-1}$ exhibited an elastic modulus of approximately $119 \mathrm{GPa}$; this value is in agreement with prior studies ${ }^{16,17)}$. For the specimen with the powder feed rate of $3 \mathrm{~g} \cdot \mathrm{min}^{-1}$, the yield strength, the ultimate tensile strength (UTS), and the elongation were observed to be approximately $950 \mathrm{MPa}, 1049 \mathrm{MPa}$, and

(a)
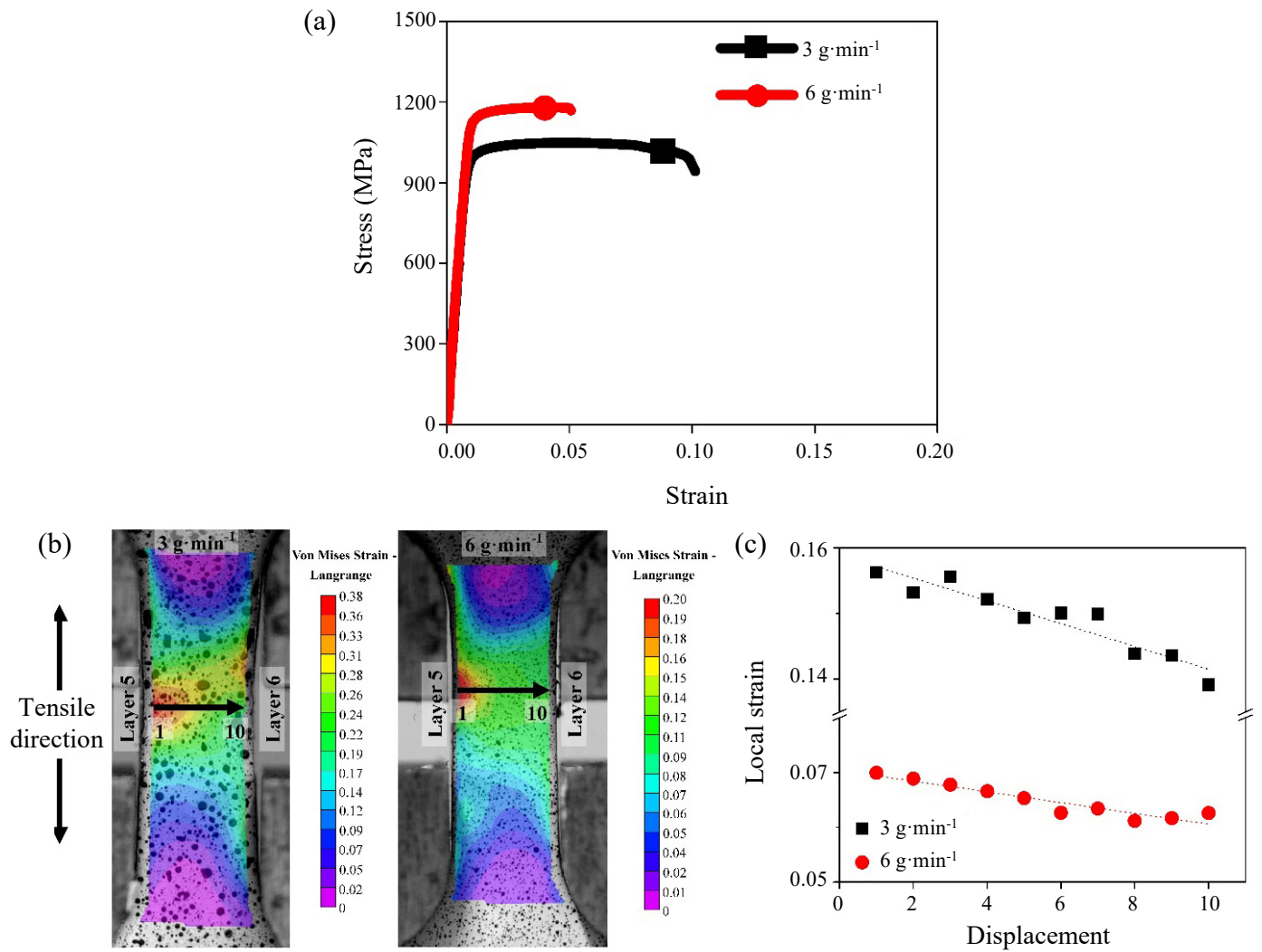

Fig. 5 (a) Engineering stress-strain curves of the specimens with the powder feed rates of 3 and $6 \mathrm{~g} \cdot \mathrm{min}^{-1}$, (b) Von-Mises strain distribution for the tensile specimens, analyzed by DIC, (c) Engineering local strain distribution in the specimens with the powder feed rates of $3 \mathrm{~g} \cdot \mathrm{min}^{-1}$ and $6 \mathrm{~g} \cdot \mathrm{min}^{-1}$ along the black arrows in (b) between the $5^{\text {th }}$ and $6^{\text {th }}$ layers 
$10.1 \%$, respectively. Meanwhile, the specimen with the powder feed rate of $6 \mathrm{~g} \cdot \mathrm{min}^{-1}$ displayed enhanced yield strength and UTS of approximately $1050 \mathrm{MPa}$ and $1180 \mathrm{MPa}$, respectively, despite an elongation reduction of $5.1 \%$. According to the tensile results, the specimen with the powder feed rates of $3 \mathrm{~g} \cdot \mathrm{min}^{-1}$ exhibited a better fracture toughness (integrated area of the stress-strain curve) than the specimen with the powder feed rate of 6 $\mathrm{g} \cdot \mathrm{min}^{-1}$.

The analysis of Von-Mises strain distribution by DIC in the DED Ti-6Al-4V tensile specimens prior to fracture is displayed in Fig. 5b. It is noticed that a higher local strain was found at layer 5 for both specimens with the powder feed rates of 3 and $6 \mathrm{~g} \cdot \mathrm{min}^{-1}$, as indicated by the red region. Meanwhile, the appearance of necking, which was adjacent to the high local strain region, occurred only in the specimen with the powder feed rate of $3 \mathrm{~g} \cdot \mathrm{min}^{-1}$, as this specimen exhibited a higher ductility. The local strain values tend to decrease gradually toward the layer 6 for both specimens (Fig. 5c). The inhomogeneity of the local strain in the gauge area was likely attributed to the different amounts of intrinsic heat energy in the DED specimens.

The fracture surface observation for the tensile specimens are presented in Fig. 6, in which the crack was initiated from layer 5 (Figs. 6a and 6b). In the specimen

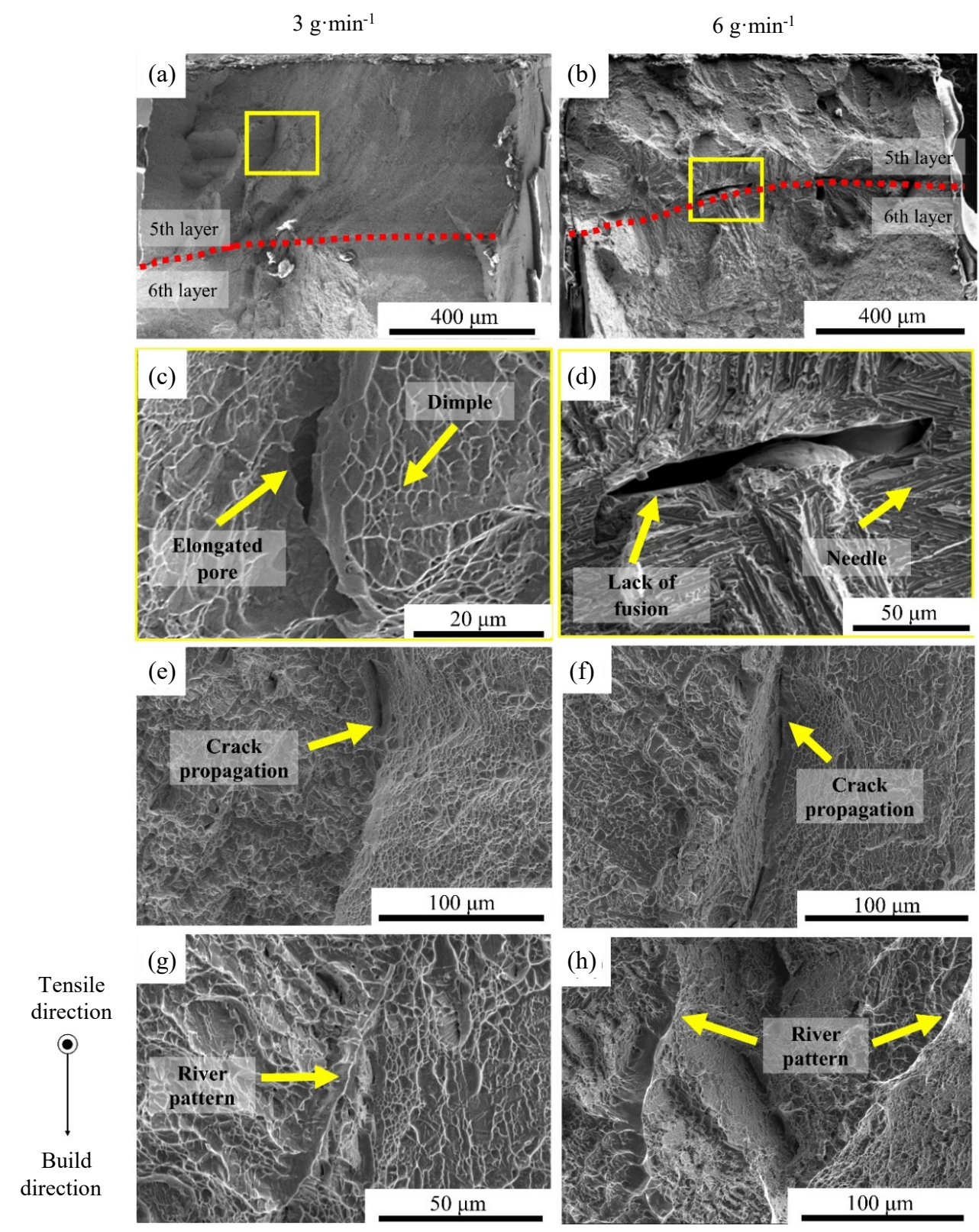

Fig. 6 (a,b) The crack initiation of specimens with the powder feed rates of 3 and $6 \mathrm{~g} \cdot \mathrm{min}^{-1}$, respectively, in the layer 5 . (c) The presence of an elongated pore and dimples, (d) The formation of lack of fusion and needle, (e,f) Crack propagation, $(\mathrm{g}, \mathrm{h})$ River patterns fracture 
with the powder feed rate of $3 \mathrm{~g} \cdot \mathrm{min}^{-1}$, the presence of an elongated pore with a size of $20 \mu \mathrm{m}$ was observed as a favorable crack initiation site (Fig. 6c). The presence of dimples further suggests a ductile fracture behavior in the specimen with the powder feed rate of $3 \mathrm{~g} \cdot \mathrm{min}^{-1}$ (Fig. 6c). Meanwhile, the formation of lack of fusion in the specimen with the powder feed rate of $6 \mathrm{~g} \cdot \mathrm{min}^{-1}$ (Fig. 6d) could act as a local stress concentration for the tensile fracture, as the defect has a sharp-edge morphology. The fracture area in the specimen with the powder feed rate of $6 \mathrm{~g} \cdot \mathrm{min}^{-1}$ exhibited a needle-shaped characteristic (Fig. 6d), indicating a brittle fracture mode. Furthermore, the crack propagation in the tensile specimens (Fig. 6e and 6f) were observed in which the crack propagated through the prior $\beta$ grain. The crack propagation through the grain is supported by the occurrence of the river pattern, which usually indicates the transgranular fracture (Figs. $6 \mathrm{~g}$ and $6 \mathrm{~h})^{18}$.

\section{Discussion}

\subsection{Role of intrinsic heat treatment on the decom- position of $a^{\prime}$ and am}

The intrinsic heat treatment corresponded to the decomposition of $\alpha^{\prime}$ and $\alpha_{\mathrm{m}}$ in the lower layers. The intrinsic heat treatment was originated through the heat conduction of the melt pool of the upper layer. Subsequently, the lower layers underwent cyclic heat conduction as a result of depositing new layers. The heat conduction rate can be calculated using the Eq. 1 as follows:

$$
\mathrm{Q}_{\text {conduction }}=\mathrm{kA} \frac{\Delta \mathrm{T}}{\Delta \mathrm{x}}\left[\mathrm{J} \cdot \mathrm{s}^{-1}\right]
$$

where $k$ is the thermal conductivity of $20 \mathrm{~W} \cdot \mathrm{m}^{-1} \cdot \mathrm{K}^{-1}$ for Ti-6Al- $4 \mathrm{~V}^{19)}, A$ is the cross-sectional area of the specimen $\left(\mathrm{m}^{2}\right), \Delta T$ is the difference between the temperature of the melt pool and the initial temperature of the pre-existing layer (assuming $298 \mathrm{~K}$ ), and $\Delta x$ is the distance between the melt pool and the pre-existing layer (m). The heat conduction rate of the specimens with the powder feed rates of 3,6 , and $9 \mathrm{~g} \cdot \mathrm{min}^{-1}$ was calculated to be approximately 6064,3383 , and $2718 \mathrm{~J} \cdot \mathrm{s}^{-1}$, respectively. This heat conduction rate can alter the microstructures of $\alpha^{\prime}$ and $\alpha_{\mathrm{m}}$ in the lower layers, as shown in Figs. 3 and 4 . The needle-shaped $\alpha$ ' was altered into $\alpha$ lamellae with the formation of $\beta$ phase at $\alpha / \alpha$ boundary. On the other hand, the sub-lamellar of $\alpha_{\mathrm{m}}$ coalesced into the continuous lamellar morphology of $\alpha / \beta$ phase to decrease the boundary energy of $\alpha_{\mathrm{m}} / \alpha_{\mathrm{m}}$ sub-lamellar ${ }^{11)}$.

\subsection{Mechanical properties due to the decompo- sition of $a^{\prime}$ and am}

The decomposition of $\alpha^{\prime}$ and $\alpha_{\mathrm{m}}$ in the lower layers affects the mechanical properties of the DED Ti-6Al-4V specimens. For the hardness result, the values are significantly lower in the lower layers. This occurred due to the morphology alteration of the $\alpha^{\prime}$ and $\alpha_{\mathrm{m}}$ by the intrinsic heat treatment, which consequently decreased hardness values. The lowest hardness was obtained in the specimen with the powder feed rate of $3 \mathrm{~g} \cdot \mathrm{min}^{-1}$, which can be related to the highest heat conduction energy in this specimen to decompose the microstructure more severely. Meanwhile, the highest hardness values in the top layer are attributed to the microstructures, which are not decomposed into $\alpha$ and $\beta$ phases. For the tensile result, the combination of lower tensile strength and higher elongation in the specimen with the powder feed rate of $3 \mathrm{~g} \cdot \mathrm{min}^{-1}$ is also related to greater heat conduction which further decomposed the microstructures. On the other hand, as the heat conduction in the specimen with the powder feed rate of $6 \mathrm{~g} \cdot \mathrm{min}^{-1}$ is approximately $44 \%$ lower than in the specimen with the powder feed rate of $3 \mathrm{~g} \cdot \mathrm{min}^{-1}$, the decomposition of the microstructure was not that severe. Thus, the specimen with the powder feed rate of $6 \mathrm{~g} \cdot \mathrm{min}^{-1}$ exhibited a higher tensile strength but lower elongation.

The microstructure decomposition also affects strain distribution, as shown in Fig. 5. The higher local strain at layer 5 was apparently also attributed to the more repeated heating in this layer, compared to that in the layer 6. Owing to more repeated heating, the microstructure at layer 5 becomes more decomposed, which cannot further accommodate the stress. Consequently, it caused the initiation of failure for both tensile specimens. Furthermore, the initiation of failure at layer 5 was also promoted by the formation of the elongated pore and the lack of fusion in the specimens with the powder feed rates of 3 and $6 \mathrm{~g} \cdot \mathrm{min}^{-1}$, respectively.

The overall comparison of mechanical properties in Ti-6Al-4V alloy fabricated by several different methods is shown in Fig. 7. The AM Ti-6Al-4V alloys processed by PBF and DED generally show higher strength due to the formation of brittle microstructures, such as $\alpha^{\prime}, \alpha_{\mathrm{m}}$, and finer prior $\beta$ grains. It is correlated to the fast cooling rate that generally takes place in PBF and DED processes. The mechanical properties of the specimen with the powder feed rate of $3 \mathrm{~g} \cdot \mathrm{min}^{-1}$ resembled the results of Ti-6Al-4V fabricated with similar DED methods. Although the specimen with the powder feed rate of $3 \mathrm{~g} \cdot \mathrm{min}^{-1}$ exhibited a lower tensile strength, it achieved a better fracture toughness compared to the 


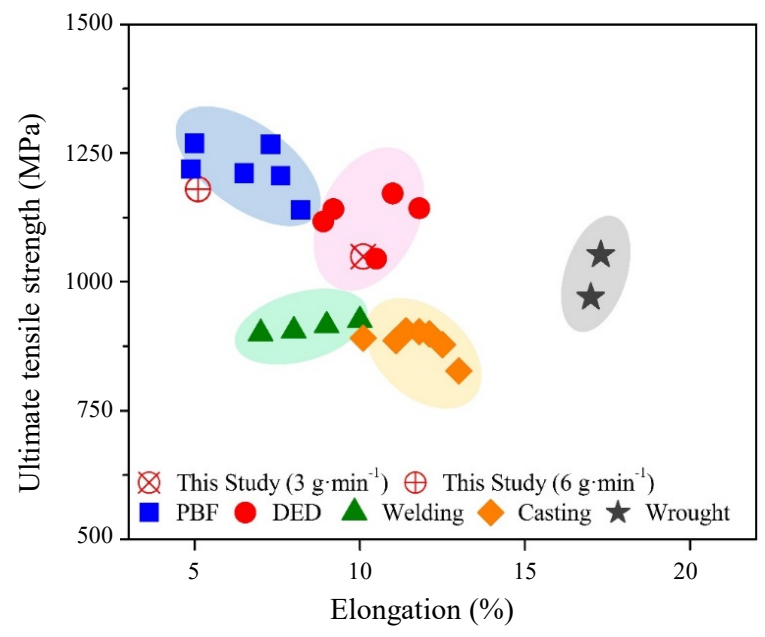

Fig. 7 The comparison of Ti-6Al-4V mechanical properies with different fabrication methods: $\mathrm{PBF}^{20-24)}$, $\mathrm{DED}^{25-27)}$, welding ${ }^{28)}$, casting $^{29)}$, and wrought ${ }^{1,30)}$

specimen with the powder feed rate of $6 \mathrm{~g} \cdot \mathrm{min}^{-1}$. The mechanical properties of the specimen with the powder feed rate of $6 \mathrm{~g} \cdot \mathrm{min}^{-1}$ resembled closer to the PBF method. This occurred due to the combination of the low heat conduction to further decompose the microstructures and the formation of lack of fusion which limits the elongation. Therefore, the optimization of proper feed rate and the post heat treatment process is needed to enhance the mechanical properties of additively manufactured Ti-6Al-4V alloy.

\section{Conclusion}

In this work, the effect of microstructure decomposition between $\alpha^{\prime}$ and $\alpha_{\mathrm{m}}$ on the mechanical properties of AM Ti-6Al-4V processed by the DED with different powder feed rates were successfully investigated. The conclusions of this work can be listed as follows.

1) The decomposition of $\alpha^{\prime}$ and $\alpha_{m}$ into $\alpha$ and $\beta$ phase in the lower layers were attributed to the repeated intrinsic heat treatment. The intrinsic heat treatment was originated from the heat conduction of the melt pool on the upper layer transferred to the lower layers.

2) The DED Ti-6Al-4V specimen with the lower powder feed rate exhibited the more severe decomposition of $\alpha^{\prime}$ and $\alpha_{\mathrm{m}}$ in the lower layers. This occurred since the lower powder feed rate caused the higher heat conduction rate transferred to the lower layers.

3) The decomposition of $\alpha^{\prime}$ and $\alpha_{m}$ significantly affected the mechanical properties of the DED Ti-6Al$4 \mathrm{~V}$. The hardness values of the deposited layers tended to decrease with the decrease in powder feed rate. Meanwhile, the mechanical properties exhibited a better fracture toughness for the specimen with the more severe decomposition related to the powder feed rate of $3 \mathrm{~g} \cdot \mathrm{min}^{-1}$.

4) The microstructure decomposition also affected the strain distribution in the DED Ti-6Al-4V tensile specimens. The more decomposed microstructures in the lower layer exhibited the higher local strain, which subsequently initiated the tensile fracture.

\section{Acknowledgment}

This work was supported by the Korea Evaluation Institute of Industrial Technology (KEIT), Granted financial resources from the Ministry of Trade, Industry, and Energy, the Republic of Korea (No. 10062485).

ORCD. Desrilia Nursyifaulkhair: https://orcid.org/0000-0002-9883-784X ORCID: Nokeun Park: https://orcid.org/0000-0002-7863-1457

ORCID: Eung Ryul Baek: https://orcid.org/0000-0002-1705-342X

\section{References}

1. M. J. Donachie, Titanium - A Technical Guide, (2000). https://doi.org/10.5772/1844

2. G. Lütjering, Influence of processing on microstructure and mechanical properties of $(\alpha+\beta)$ titanium alloys, Mater. Sci. Eng. A. 243 (1998) 32-45. https://doi.org/10.1016/s0921-5093(97)00778-8

3. A. Dehghan-Manshadi, M. H. Reid, and R. J. Dippenaar, Effect of microstructural morphology on the mechanical properties of titanium alloys, J. Phys. Conf. Ser. 240 (2010). https://doi.org/10.1088/1742-6596/240/1/012022

4. S. Liu and Y. C. Shin, Additive manufacturing of Ti6Al4V alloy: A review, Mater. Des. 164 (2019) 107552. https://doi.org/10.1016/j.matdes.2018.107552

5. G. Lutjering and J. C. Williams, Titanium, in: Titanium, Springer-Verlag, (2007). https://doi.org/10.1007/978-3-540-73036-1

6. Y. Byun, S. Lee, S. M. Seo, J. T. Yeom, S. E. Kim, N. Kang, and J. Hong, Effects of $\mathrm{Cr}$ and $\mathrm{Fe}$ addition on microstructure and tensile properties of Ti-6Al-4V prepared by direct energy deposition, Met. Mater. Int. 24 (2018) 1213-1220.

https://doi.org/10.1007/s12540-018-0148-x

7. J. Byun, H. Yi, S. Cho, D. I. Division, and H. R. Company, The effect of interpass peening on mechanical properties in additive manufacturing of Ti-6A14V, J. Weld. Join. 35 (2017) 6-12. https://doi.org/10.5781/JWJ.2017.35.2.2

8. B. Dutta and F. H. (Sam. Froes, The additive manufacturing (AM) of titanium alloys, Met. Powder Rep. 72 (2017) 96-106. https://doi.org/10.1016/j.mprp.2016.12.062

9. T. H. Lee, J. H. Oh, and D. Kam, Evaluation of SS 275 Substrate Substitutability in Arc and Wire Additive 
Manufacturing of Inconel 718, J. Weld. Join. 37 (2019) 62-68. https://doi.org/10.5781/JWJ.2019.37.1.8

10. D. Nursyifaulkhair, N. Park, E. R. Baek, and S. Kim, Influence of cooling rate on volume fraction of $\alpha$ massive phase in a Ti-6Al-4V alloy fabricated using directed energy deposition, Mater. Lett. 257 (2019) 126671 . https://doi.org/10.1016/j.matlet.2019.126671

11. G. Suprobo, A. A. Ammar, N. Park, E. R. Baek, and S. Kim, Thermal decomposition of massive phase to fine lamellar $\alpha / \beta$ in Ti-6Al-4V additively manufactured alloy by directed energy deposition, Met. Mater. Int. (2019) 1-8. https://doi.org/10.1007/s12540-019-00304-4

12. W. Xu, M. Brandt, S. Sun, J. Elambasseril, Q. Liu, K. Latham, K. Xia, and M. Qian, Additive manufacturing of strong and ductile Ti-6Al-4V by selective laser melting via in situ martensite decomposition, Acta Mater. 85 (2015) 74-84. https://doi.org/10.1016/j.actamat.2014.11.028

13. Z. Liu, S. L. Lu, H. P. Tang, M. Qian, and L. Zhan, Characterization and decompositional crystallography of the massive phase grains in an additivelymanufactured Ti-6Al-4V alloy, Mater. Charact. 127 (2017) 146-152. https://doi.org/10.1016/j.matchar.2017.01.012

14. G. Suprobo, N. Park, and E. R. Baek, Effect of double stage solution treatment on the volume fraction of massive phase $(\alpha \mathrm{m})$ as a new method to obtain a fine lamellar $\alpha / \beta$ in Ti-6Al-4V alloy, Intermetallics. 113 (2019) 106581. https://doi.org/10.1016/j.intermet.2019.106581

15. M. I. Utama, N. Park, and E. R. Baek, Microstructure and mechanical features of electron beam welded dissimilar titanium alloys: Ti-10V-2Fe-3Al and Ti-6Al4V, Met. Mater. Int. 25 (2019) 439-448. https://doi.org/10.1007/s12540-018-0197-1

16. M. Simonelli, Y. Y. Tse, and C. Tuck, Effect of the build orientation on the mechanical properties and fracture modes of SLM Ti-6Al-4V, Mater. Sci. Eng. A. 616 (2014) 1-11. https://doi.org/10.1016/j.msea.2014.07.086

17. B. J. Hayes, B. W. Martin, B. Welk, S. J. Kuhr, T. K. Ales, D. A. Brice, I. Ghamarian, A. H. Baker, C. V. Haden, D. G. Harlow, H. L. Fraser, and P. C. Collins, Predicting tensile properties of Ti-6Al-4V produced via directed energy deposition, Acta Mater. 133 (2017) 120-133. https://doi.org/10.1016/j.actamat.2017.05.025

18. G. A. Pantazopoulos, A short review on fracture mechanisms of mechanical components operated under industrial process conditions: Fractographic analysis and selected prevention strategies, Metals (Basel). 9 (2019).

https://doi.org/10.3390/met9020148
19. A. Raghavan, H. L. Wei, T. A. Palmer, and T. DebRoy, Heat transfer and fluid flow in additive manufacturing, J. Laser Appl. 25 (2013) 052006. https://doi.org/10.2351/1.4817788

20. D. A. Hollander, M. Von Walter, T. Wirtz, R. Sellei, B. Schmidt-Rohlfing, O. Paar, and H. J. Erli, Structural, mechanical and in vitro characterization of individually structured Ti-6Al-4V produced by direct laser forming, Biomaterials. 27 (2006) 955-963. https://doi.org/10.1016/j.biomaterials.2005.07.041

21. L. Facchini, E. Magalini, P. Robotti, A. Molinari, S. Höges, and K. Wissenbach, Ductility of a Ti-6Al-4V alloy produced by selective laser melting of prealloyed powders, Rapid Prototyp. J. 16 (2010) 450-459. https://doi.org/10.1108/13552541011083371

22. T. Vilaro, C. Colin, and J. D. Bartout, As-fabricated and heat-treated microstructures of the Ti- $6 \mathrm{Al}-4 \mathrm{~V}$ alloy processed by selective laser melting, Metall. Mater. Trans. A Phys. Metall. Mater. Sci. 42 (2011) 3190-3199. https://doi.org/10.1007/s11661-011-0731-y

23. B. Vrancken, L. Thijs, J. P. Kruth, and J. Van Humbeeck, Heat treatment of Ti6Al4V produced by selective laser melting: microstructure and mechanical properties, J. Alloys Compd. 541 (2012) 177-185. https://doi.org/10.1016/j.jallcom.2012.07.022.

24. H. K. Rafi, N. V. Karthik, H. Gong, T. L. Starr, and B. E. Stucker, Microstructures and mechanical properties of Ti6Al4V parts fabricated by selective laser melting and electron beam melting, J. Mater. Eng. Perform. 22 (2013) 3872-3883. https://doi.org/10.1007/s11665-013-0658-0

25. S. Asadi, T. Saeid, A. Valanezhad, I. Watanabe, and J. Khalil-Allafi, The effect of annealing temperature on microstructure and mechanical properties of dissimilar laser welded superelastic NiTi to austenitic stainless steels orthodontic archwires, J. Mech. Behav Biomed, 109 (2020) 103818. https://doi.org/10.1016/j.jmbbm.2020.103818

26. J. Alcisto, A. Enriquez, H. Garcia, S. Hinkson, T. Steelman, E. Silverman, P. Valdovino, H. Gigerenzer, J. Foyos, J. Ogren, J. Dorey, K. Karg, T. McDonald, and O. S. Es-Said, Tensile properties and microstructures of laser-formed Ti-6Al-4V, J. Mater. Eng. Perform. 20 (2011) 203-212. https://doi.org/10.1007/s11665-010-9670-9

27. E. Amsterdam and G. A. Kool, High cycle fatigue of laser beam deposited Ti-6Al-4V and inconel 718, ICAF 2009, Bridg. Gap Between Theory Oper. Pract. - Proc. 25th Symp. Int. Comm. Aeronaut. Fatigue. (2009) 1261-1274. https://doi.org/10.1007/978-90-481-2746-7_71

28. Y. Zhang, Y. S. Sato, H. Kokawa, S. H. C. Park, and S. Hirano, Microstructural characteristics and mechanical properties of Ti-6Al-4V friction stir welds, Mater. Sci. Eng. A. 485 (2008) 448-455. https://doi.org/10.1016/j.msea.2007.08.051 
29. A. du Plessis, I. Yadroitsava, S. G. le Roux, I. Yadroitsev, J. Fieres, C. Reinhart, and P. Rossouw, Prediction of mechanical performance of Ti6Al4V cast alloy based on microCT-based load simulation, J. Alloys Compd. 724 (2017) 267-274.

https://doi.org/10.1016/j.jallcom.2017.06.320
30. B. E. Carroll, T. A. Palmer, and A. M. Beese, Anisotropic tensile behavior of Ti-6Al-4V components fabricated with directed energy deposition additive manufacturing, Acta Mater. 87 (2015) 309-320.

https://doi.org/10.1016/j.actamat.2014.12.054 